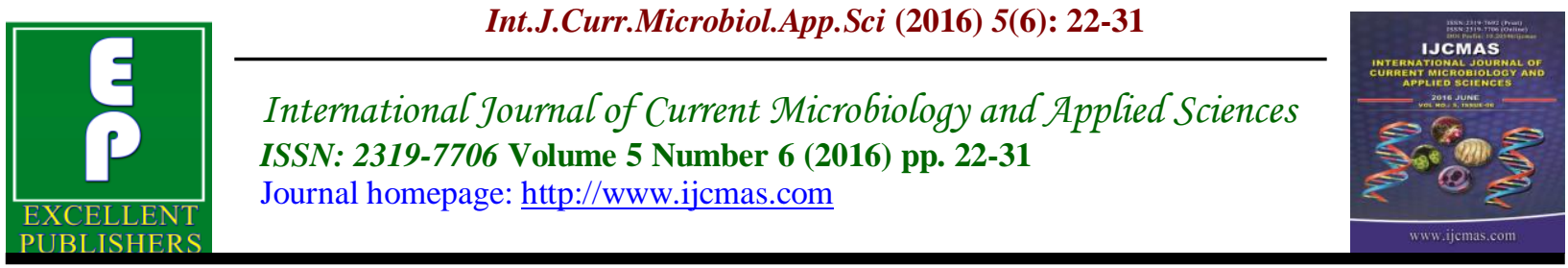

Original Research Article

http://dx.doi.org/10.20546/ijcmas.2016.506.003

\title{
Comparative Study of Plastic and Polymer Degrading Bacillus megaterium and Aspergillus niger Isolated from Dumped Plastic Waste
}

\author{
S. Bhuvaneswari ${ }^{1 *}$, G. Subashini ${ }^{1}$ and R. Sarojini ${ }^{2}$ \\ ${ }^{1}$ Assistant Professor, Department of Microbiology, Shrimati Indira Gandhi College, \\ Trichy-2, India \\ ${ }^{2}$ Department of Microbiology, Shrimati Indira Gandhi College, Trichy-2, India \\ *Corresponding author
}

\begin{abstract}
A B S T R A C T
Keywords

Biodegradation,

Plastics,

Bacillus sp.,

Aspergillus,

PCR.

\section{Article Info}

Accepted:

07 May 2016

Available Online:

10 June 2016

Plastics and their use has become a part in all sectors of economy. The word plastic comes from the Greek word 'plastikos', which means, able to be molded into different shapes. This study has covered the major concerns about the natural and synthetic polymers, their types, uses and degradability. The present study deals with the isolation, identification and degradative ability of plastic degrading microorganisms from soil. Different types of changes are produced by the microorganism during morphological and biochemical analysis. Synthetic plastic sample collected from the dumped soil of garden was used in this study. The morphology of the isolates was observed and genus was identified by biochemical tests as Bacillus sp. and Aspergillus sp. In the study, pieces of plastics and synthesized PES membrane were inoculated in the liquid culture medium and kept for 1 month to observe the percentage of weight loss by bacteria and fungi. The percentage of weight loss due to degradation was found more by Bacillus. This shows greater potential of degradation compared to Aspergillus. The preliminary screening of biodegradation capability was done by Fourier Transform Infra-Red (FTIR) Spectroscopy and SEM (Scanning electron microscopy) analysis. Target DNA from isolated strain was submitted for 16S rRNA sequencing after which BLAST and phylogenetic analysis have to be carried out.
\end{abstract}

\section{Introduction}

Plastics are defined as the polymers (solid materials) which on heating become mobile and can be cast into moulds. They are nonmetallic moldable compounds and the materials that are made from into any desired shape and sizes. The word plastic comes from the Greek word 'plastikos', which means, 'able to be molded into different shapes'. The plastics we use are
Made from, inorganic and organic raw material such as carbon, silicon, etc., Basic material used for making plastic are extracted from coal, oil and natural gas. Plastics and their use has become a part in all sectors of economy.. Plastics are also used in packaging of products such as food, pharmaceuticals, cosmetics, detergents and chemicals. Approximately $30 \%$ of plastics are used worldwide for packaging 
applications and the most widely used plastics used for packaging are polyethylene (LDPE, MDPE, HDPE, and LLDPE), polypropylene (PP), polystyrene (PS), polyvinyl chloride (PVC), polyurethane (PUR), polybutylene terephthalate (PBT) and nylons tons (Gautam et al., 2007).

Polyethylene is widely used for various onetrip applications like food packaging, retail industry uses and agricultural uses. These applications lead to a large quantity of plastic waste, causing serious environmental problems. PE is the most problematic plastic that is resistant to microbial attack. Polyethylene subjected to 26 days of artificial UV irradiation before being buried in soil evolved less than $0.5 \%$ carbon by weight after 10 years (Kyriako and Briassoulis, 2007). Polyethersulfone (PES) is a heat-resistant, transparent, amber, noncrystalline engineering plastic. PES is a tough and rigid resin similar to conventional engineering plastics, such as polycarbonate, at room temperature. Biodegradation (i.e. biotic degradation) is a chemical degradation of materials (i.e. polymers) provoked by the action of microorganisms such as bacteria, fungi and algae. The most common definition of a biodegradable polymer is "a degradable polymer wherein the primary degradation mechanism is through the action of metabolism by microorganisms" (Sivan, 2011). Biodegradation is considered a type of degradation involving biological activity. Biodegradable polymers used for producing biodegradable agricultural films include copolyesters, poly (vinyl) alcohol, poly (vinyl) chloride, acylated starch-plastic, modified starch and vegetable oil.

The purpose of this study was to isolate microorganisms from dumped soil area and screening of the potential polyethylene degrading microorganisms and identifying the high potential microorganism that degrades the plastics.

Bacteria important in the biodegradation process include Bacillus (capable of producing thick-walled endospores that are resistant to heat, radiation and chemical disinfection), Pseudomonas, Klebsiella, Actinomycetes, Nocardia, Streptomyces, Thermoactinomycetes, Micromonospora, Flavobacterium, Comamonas, Escherichia, Azotobacter and Alcaligenes(some of them can accumulate polymer up to $90 \%$ of their dry mass). Temperature is one of the most important factors affecting microbial growth. Also important are sources of carbon and nitrogen, and $\mathrm{pH}$. Fungi active in the biodegradation process are Sporotrichum, Talaromyces, Phanerochaete, Ganoderma, Thermoascus, Paecilomyces, Thermomyces, Geotrichum, Cladosporium, Phlebia, Trametes, Chaetomium, and Aerobasidium. The biodegradation process can be divided into (1) aerobic and (2) anaerobic degradation. The purpose of this study was to isolate microorganisms from dumped soil area and screening of the potential polyethylene degrading microorganisms and identifying the high potential microorganism that degrades the plastics.

\section{Materials and Methods}

\section{Sample Collection}

Plastic sample was collected from the dumped garden soil in Mannachanallur at Tiruchirappalli.

\section{Isolation of Plastic Degrading Microorganisms}

To isolate the plastic degrading bacteria and fungi, serial dilution was done in the range of $10^{-1}$ to $10^{-10} \cdot 10^{-4}$ to $10^{-7}$ dilutions of the 
sample were then spread on nutrient agar and incubated at $37^{\circ} \mathrm{C}$ for 1-2 days for bacterial growth. Simultaneously, $10^{-2}$ to $10^{-}$ 5 dilutions were spread on potato dextrose agar and incubated at $28^{\circ} \mathrm{C}$ for 5-7 days for facilitating fungal growth. After incubation, the numbers of colonies were counted The single colonies were picked and repeatedly streaked on nutrient agar medium and potato dextrose agar. Grown colonies were investigated for their morphological characteristics, cultural and biochemical characteristics following Bergey's Manual of Determinative Bacteriology (1994).

\section{Identification of Isolates}

Identification of the isolates were subjected to Gram staining and specific biochemical tests following Bergey's Manual of Systematic Bacteriology (Kandler and Weiss, 1986).

\section{Morphological Identification}

Bacterial smear was prepared for each of the isolates by Gram Staining and Motility test was done.various Biochemical tests for bacteria was performed by the methodology (Kloos and Jorgensen, 1985) tests such as the Indole Production Test, Methyl Red Test, Voges-Proskauer's Test, Citrate Utilization Test, Triple Sugar Iron Test, Catalase Test, Urease Test, Oxidase Test, Nitrate Reduction Test Gas production from glucose was assessed by inoculating the isolated strains in MRS broth containing glucose in a Durham tube in inverted condition and incubated at $37^{\circ} \mathrm{C}$ for $48-72$ hrs. The upward movement of inverted Durham tube indicates positive reaction (gas production).

\section{Fungal Identification Procedures}

\section{Lactophenol Mount (Leck 1999)}

A small drop of lactophenol (LP) was placed on a clean glass microscope slide. small portion of the colony was placed into the drop of LP. A clean cover glass was placed over the suspension and observed microscopically.

\section{Germ Tube Test (Sheppard 2008)}

A germ tube represents the initiation of a hypha directly from the yeast cell. Germ tube formation is influenced by the medium, inoculum size and temperature of incubation. Commercially available germ tube solution (Remel Lenexa kansa) are to be used as the medium for the test.cells were suspended in the serum and the stick was discarded. The sample was incubated at $35^{\circ}$ $\mathrm{C}$ for 2.5-3 hours and then examined with a microscope using to confirm the presence or absence of germ tubes.

\section{Pre Treatment of Plastics}

Plastic sample was treated for 6 days with nitric acid (99.0\%) and inoculated in the pure bacterial culture obtained. The flasks were then incubated at $30^{\circ} \mathrm{c}$ and $150 \mathrm{rpm}$ for 1 month. After incubation, PE pieces were analyzed for any chemical or structural change by FTIR.

\section{Polymer Membrane Preparation}

Polyethersulfone (PES) (15 wt \%) was dissolved in NMP (75 wt \%) with stirring, and either Polyethylene glycol (PEG) (10 wt $\%$ ) was added to the polymer solution. Slight heating $\left(\sim 45^{\circ} \mathrm{C}\right)$ was used during dissolution of PEG. The homogenous polymer solution was left. The polymer solution was cast with a thickness of $200 \mu \mathrm{m}$ on a glass substrate (casting speed $25 \mathrm{~mm} / \mathrm{s}$ ) and subjected to humid air $(\mathrm{RH}=50-60 \%)$ for $1 \mathrm{~min}$. The proto-membrane was solidified in a coagulation bath containing water $\left(20^{\circ} \mathrm{C}\right)$ for 1 hour. The resulting 
membranes were washed and soaked in the water for $24 \mathrm{~h}$ before drying.

\section{Microbial Degradation Studies}

\section{Determination of Weight Loss}

Pre-weighed samples of 1-cm diameter were aseptically transferred to the conical flasks containing culture broth. Control was maintained with plastic discs in the microbefree medium and all the flasks were kept in a shaker. After one month of shaking, the plastic discs were collected, and then weighed for estimation of final weight. From the data collected, the bacterial and fungal pure culture was calculated.

Sturm Test for the Analysis of Biodegradation by $\mathrm{CO}_{2}$ evolution (Muller et al., 1992)

$\mathrm{CO}_{2}$ evolution as a result of LDPE, PU, PHB and PHBV biodegradation was determined by sturm test (Muller et al., 1992). The samples were added to the culture bottle (Test bottle) with medium. Pure bacterial culture obtained was used for degradation of the samples. The test was performed at room temperature $\left(30^{\circ} \mathrm{C}\right)$ for 4 weeks. After 4 weeks of culturing, the change was observed with rising of amount of samples because of $\mathrm{CO}_{2}$ production. Evolution of $\mathrm{CO}_{2}$ as a result of degradation was trapped in the bottles.

\section{Analytical Methods}

\section{Fourier Transform Infra-Red (FTIR) Spectroscopy}

Fourier Transform Infra-Red (FTIR) analysis was done to detect the degradation of samples after culturing the liquid media, on the basis of changes in the functional groups. The pieces were mixed with $\mathrm{KBr}$ and made into a tablet which was fixed to the FTIR sample plate. Spectra were taken at 400 to 4000 waves - number $\mathrm{cm}^{-1}$ for each sample.

\section{Scanning Electron Microscopy}

The surface morphology of the degraded samples was analyzed through Scanning Electron Microscopy to check for any structural changes in the samples were mounted on the Al stubs by silver paint. Silver coating was carried out in vacuum by evaporation. The images of the samples were compared with those recorded on the original untreated samples.

\section{Isolation of DNA from Isolated Bacteria}

From the isolated bacterial cultures DNA was isolated by standard procedures (Marmurs method) and then it was subjected to Agarose Gel Electrophoresis. Agarose gel $(0.8 \%)$ was prepared and then the isolated DNA sample and molecular weight DNA marker were loaded. The samples were run for $1 \mathrm{~h}$ at $100 \mathrm{~V}$ and DNA was visualized by exposure to UV transilluminator.

\section{Quantification of DNA}

About $4 \mu 1$ of the DNA sample was mixed with $2996 \mu 1$ of TE buffer and its absorbance was read at $260 \mathrm{~nm}$ by using UV - Visible spectrophotometer. $3 \mathrm{~mL}$ of TE buffer served as a blank. An optical density was calibrated (Sambrook et al., 1989). Based on the OD value, DNA sample was quantified.

The Quantity of DNA $(n g / \mu l)=$

Optical Density at 260nm X 50 X Dilution factor 1000

\section{PCR Amplification for 16S rRNA}

The DNA was amplified by using universal $16 \mathrm{~S}$ rRNA primers forward primer; $8 \mathrm{~F}$ and reverse primer; 1492R (McCaig et al., 
1999). PCR reaction were performed in a $50 \mu \mathrm{L}$ containing $0.1 \mathrm{ng}$ of template DNA, PCR Master Mixer, $10 \mathrm{pmol}$ concentration of each primer and $0.025 \mathrm{U}$ of Taq DNA polymerase enzymes. The final volume was adjusted with sterilized Mili-Q water. A PCR thermocycler was used to amplify the reactions through an initial denaturation step consisting of $94^{\circ} \mathrm{C}$ for $2 \mathrm{~min}$ followed by 25 cycles at $94^{\circ} \mathrm{C}$ for $1 \mathrm{~min}, 52.3^{\circ} \mathrm{C}$ for $1 \mathrm{~min}$ and with an extension of $72^{\circ} \mathrm{C}$ for $1 \mathrm{~min}$ followed by an final extension temperature at $72^{\circ} \mathrm{C}$ for 2 min (Chandler et al., 1997). Then amplified PCR products were stored at $-20^{\circ} \mathrm{C}$ for further purification and downstream application.

\section{Primers for 16S rRNA Amplification}

$\begin{array}{lll}\text { SetA } & 16 \mathrm{~S} & \text { AGAGTTTGATCCTGGCTCAG } \\ 8 \mathrm{~F} & \text { rRNA } & \\ \text { SetA } & 16 \mathrm{~S} & \text { TACGGCTACCTTGTTACGACTT } \\ \text { 1492R } & \text { rRNA } & \end{array}$

\section{Agarose Gel Electrophoresis OF PCR Product}

About $5 \mu \mathrm{l}$ aliquot of PCR amplified product was loaded on $1.4 \%$ agarose in $1 \mathrm{X}$ TAE buffer at $50 \mathrm{~V}$ for $45 \mathrm{~min}$ and the PCR products were visualized in a UV transilluminator. Lambda DNA double digested with EcoR I and Hind III was used as a marker.

\section{Purification of the Amplified PCR Product}

Purification of amplified PCR product was done using a DNA purification kit (HiYiled $^{\mathrm{TM}}$ Gel /PCR DNA extraction KitReal Genomics, Taiwan). To $45 \mu 1$ of the amplified PCR product, $500 \mu 1$ of DF buffer (supplied in the Kit) was mixed by vortexing. The mixture was mixed well by pipetting and allowed to stand for $1 \mathrm{~min}$. The mixture was added to a DE column.The column was transferred to a sterile centrifuge tube and $30 \mu 1$ of elution buffer was added in the center of the column and kept for 30sec until the elution buffer was absorbed by the matrix. The column was spun for $2 \mathrm{~min}$ at $12,000 \mathrm{rpm}$ to elute the purified DNA and stored at $-20^{\circ} \mathrm{C}$.

\section{Phylogenetic Analysis of 16S rRNA}

The 16S rRNA sequencing of isolated bacteria was carried out at. The sequencing reactions were run on AMI-PRISM automated sequencer- ABI-3730 DNA analyzer (Applied Bio systems, USA). The nucleotide sequence was initially analyzed at Blast-n site in NCBI server and corresponding sequences were down loaded. The alignment of the sequences was done using ClustalX software program. The phylogenetic tree was constructed using the aligned sequences by the neighbor joining method using MEGA 4 software (Tamura et al., 2007).

\section{Result and Discussion}

This study has covered the major concerns about the natural and synthetic polymers, their types, uses and degradability. Another area examined has been the biodegradation of plastics by the liquid culture method. The present study deals with the isolation, identification and degradative ability of plastic degrading microorganisms from soil. Different types of changes are produced by the microorganism during morphological and biochemical analysis. Synthetic plastic sample collected from the dumped soil of garden was used in this study and was subjected to serial dilution. After appropriate incubations a bacterial colony and fungal mycelium were observed. By frequent sub culturing, the single pure cultures were isolated and stored at $4{ }^{\circ} \mathrm{C}$ (plate 1). The morphology of the isolates was observed and genus was identified by biochemical tests as Bacillus sp (Table 1) and Aspergillus 
sp (plate2). Bacillus is the most common

biodegradation (Bhardwaj et al., 2012).

bacteria associated with plastic

Table.1 Characterization of the Bacterial Isolate

\begin{tabular}{|l|l|c|}
\hline S.No & Parameters & Results \\
\hline 1 & Gram's staining & +(rod) \\
\hline 2 & Shape & Rod \\
\hline 3 & Motility & - \\
\hline 4 & Indole & - \\
\hline 5 & Methyl red & + \\
\hline 6 & VP & - \\
\hline 7 & TSI & + \\
\hline 8 & Citrate & - \\
\hline 9 & Urease & - \\
\hline 10 & Oxidase & + \\
\hline 11 & Catalase & Bacillus $\mathbf{s p}$. \\
\hline 12 & Nitrate & \\
\hline 15 & Strain name & \\
\hline
\end{tabular}

Table.2 Table.1 Characterization of the Bacterial Isolate

\begin{tabular}{|c|c|c|c|c|c|c|}
\hline \multirow[t]{2}{*}{ Sample } & \multicolumn{3}{|c|}{ Bacillus } & \multicolumn{3}{|c|}{ Aspergillus } \\
\hline & $\begin{array}{c}\text { Initial wt } \\
(\mathrm{mg})\end{array}$ & $\begin{array}{c}\begin{array}{c}\text { Final wt } \\
(\mathrm{mg})\end{array} \\
\text { (1) }\end{array}$ & $\begin{array}{c}\% \\
\text { degradation }\end{array}$ & $\begin{array}{c}\text { Initial wt } \\
(\mathrm{mg})\end{array}$ & $\begin{array}{c}\text { Final wt } \\
\text { (mg) }\end{array}$ & $\begin{array}{c}\% \\
\text { degradation }\end{array}$ \\
\hline Pretreated plastic & 568 & 554.7 & 2.34 & - & - & - \\
\hline Untreated plastic & 511 & 505.8 & 1.018 & 550 & 548 & 0.364 \\
\hline Polymer membrane & 91.5 & 91 & 0.5 & - & - & - \\
\hline
\end{tabular}

Plate.1 Pure culture of Bacillus species

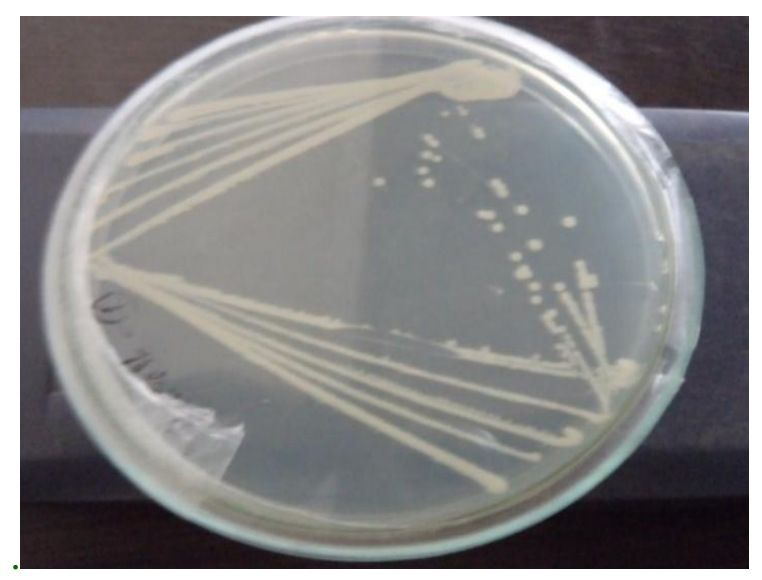


Plate $210-^{5}$ dilution of dumped soil plated on fungal growth

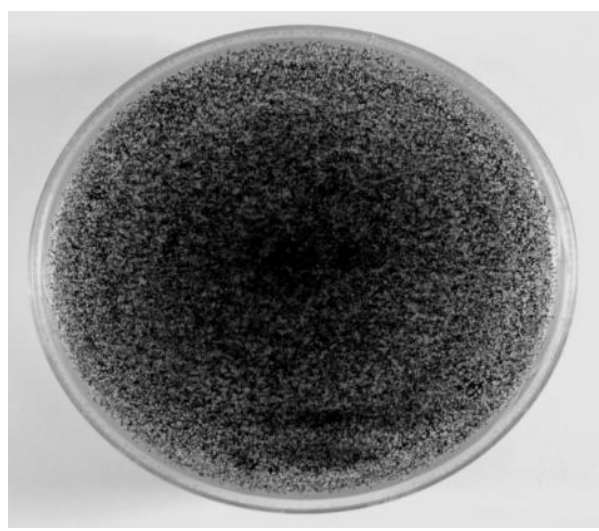

Plate.3 Plastic inoculated into Bacillus liquid culture for Biodegradation studies

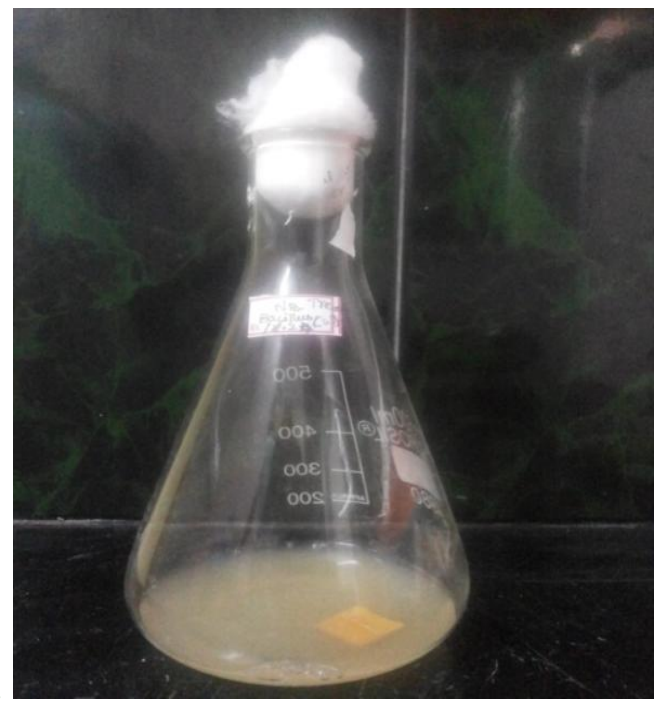

Fig.1 FTIR Spectra of Polymer Membrane Degraded by Bacillus sp

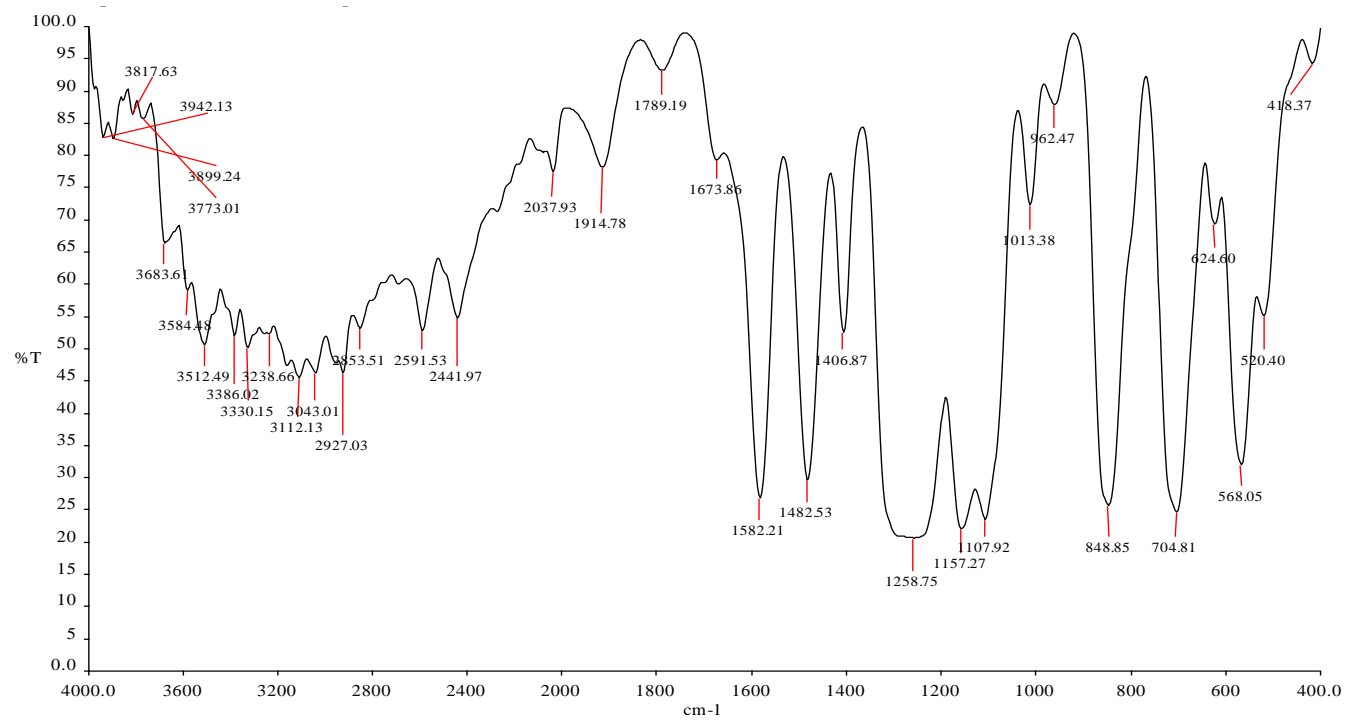


Fig.2 PCR Amplification of 16s rRNA

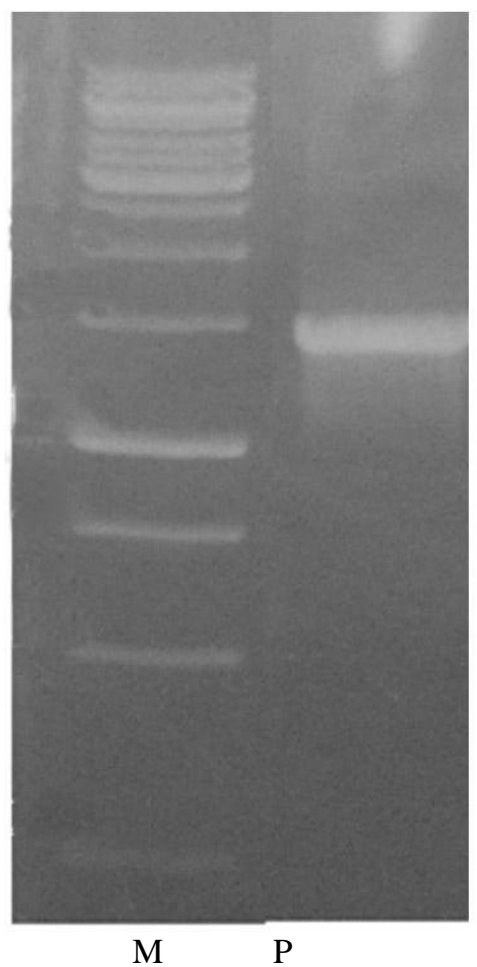

M-Marker(1kb ladder,P-PCRProducts(1500bp)

In the present study, pieces of plastics and synthesized PES membrane in the liquid culture medium containing bacterial and fungal isolates and kept for 1 month to observe the percentage of weight loss by bacteria and fungi The percentage of weight loss due to degradation was found more by Bacillus. (plate2)This shows it has the greater potential of degradation compared to Aspergillus (Table 2). Usha et al., 2011 who have reported a higher degradation of plastic by bacteria compared to fungi. The evolution of $\mathrm{CO}_{2}$ showed the breakdown of plastics by microbial activity.

The preliminary screening of biodegradation capability was done by Fourier Transform Infra-Red (FTIR) Spectroscopy (figure 3) for surface changes (Deyal et al., 2012).

The changes in the spectra confirmed the degradation occurred. In case of control, peak appeared at $1315.93 \mathrm{~cm}^{-1}$ but it disappeared after microbial treatment. In peak at $1768.72 \mathrm{~cm}^{-1}$ in control was reduced to $1760.23 \mathrm{~cm}^{-1}$, thus indicating the breakdown of $\mathrm{C}=\mathrm{O}$ bond. In case of test, the formation of new peaks in the region of $1417-827 \mathrm{~cm}^{-1}$ indicates the formation of the $\mathrm{C}-\mathrm{C}$ due to the breakdown of $\mathrm{C}-\mathrm{H}$ bonds.

Further SEM (Scanning electron microscopy) analysis confirmed the degradation of plastic and polymer by revealing the presence of porosity of the bacterial degraded surface compared to control.Thus, surface analysis of plastics after microbial treatment show many differences in morphology.

A distinct PCR product of the $1500 \mathrm{bp}$ (Figure 4) size was produced when target DNA from isolated strain was used. Further, the amplicon was submitted for $16 \mathrm{~S}$ 
rRNA sequencing after which BLAST and phylogenetic analysis have to be carried out.

In conclusion, the present study dealt with the isolation, identification and degradative abilities of plastic degrading microorganisms from soil. Synthetic plastic sample collected from the dumped soil of garden was used in this study. The morphologies of the isolates were observed and genus was identified by biochemical tests as Bacillus $s p$ and Aspergillus sp. Polyether sulfone (PES) polymer membrane was prepared and it was subsequently used to study biodegradation by Bacillus. In the present study, pieces of plastics and synthesized PES membrane were inoculated in the liquid culture medium containing bacterial and fungal isolates and kept for 1 month to observe the percentage of weight loss by bacteria and fungi. The percentage of weight loss due to degradation was found more by Bacillus. This shows it has the greater potential of degradation compared to Aspergillus.

The preliminary screening of biodegradation capability was done by FTIR Spectroscopy. The changes in the spectra of the degraded samples confirmed the degradation occurred. Further, SEM analysis confirmed the degradation of plastic and polymer by revealing the presence of porosity and fragility of the bacterial degraded surface compared to control. A distinct PCR product of 1500 bp was produced when target DNA and the amplicon was submitted for $16 \mathrm{~S}$ rRNA sequencing after which BLAST and phylogenetic analysis have to be carried out for species identification.

\section{References}

Bhardwaj, H., Gupta, R., Tiwari, A. 2012. Microbial Population Associated With Plastic Degradation. 1: 272.
Chandler, D.P., Fredrickson, J.K., Brockman, F.J. 1997. Effect of PCR template concentration on the composition and distribution of total community $16 \mathrm{~S}$ rDNA clone libraries, Mol. Ecol., Volume 6, Issue 5, pages 475-482.

Deyal, U., Naba Kumar Mondal, Kousik Das, Shampa Dutta. 2012. An approach to polymerdegradation through microbes, IOSR J. Pharmacy, Vol. 2, Issue 3, pp.385388.

Gautam, R., Bassi, A.S., Yanful, E.K., 2007. A Review of Biodegradation of Synthetic Plastic and Foams. Appl. Biochem. Biotechnol., pp. 141.

Kandler, O., Weiss, N. 1986. In: Bergey's Manual of Systematic Bacteriology, P. H. A. Sneath, N. S. Mair, M. E. Sharpe, J. G. Holt (Eds), Vol. 2, Baltimore: Williams and Wilkins, 1209 - 1234.

Kloos, W.E., Jorgensen, J.H. 1985. Manual of clinical microbiology, 4th ed. American Society for Microbiology, Washington, D.C.

Kyrikou, J., Briassoulis, D. 2007. Biodegradation of Agricultural Plastic Films: A Critical Review. J. Polym. Environ., 15: 125.

Leck, A. Preparation of lactophenol cotton blue slide mounts. Community Eye Health, 12(30): 24.

Muller, R.J., Yamada, Y. Doi. 1993. Enzymatic degradation of poly(hydroxyalkanoates by a marine bacterium. Polym. Degrad. Stab., 41: 85-91.

Sambrook, J., Fritsch, E.F., Maniatis, T. 1989. Molecular Cloning: A Laboratory Manual. Cold Spring Harbor Laboratory Press, New York.

Sheppard. 2008. Utility of the Germ Tube Test for Direct Identification of 
Candidaalbicans from Positive Blood Culture Bottles. J. Clin. Microbiol., vol. 46. 242-247.

Sivan, A. 2011. New Perspectives in plastic biodegradation. Current Opinion in Biotechnol., 22: 422-426.
Tamura, K., Dudley, J., Nei, M., Kumar, S. 2007. Molecular Evolutionary Genetics Analysis (MEGA)Software Version 4.0. Mol. Biol. Evol., 24(8): 1596-1599.

\section{How to cite this article:}

Bhuvaneswari, S., G. Subashini1 and Sarojini, R. 2016. Comparative Study of Plastic and Polymer Degrading Bacillus megaterium and Aspergillus niger isolated from dumped plastic waste. Int.J.Curr.Microbiol.App.Sci. 5(6): 22-31. doi: http://dx.doi.org/10.20546/ijcmas.2016.506.003 